BIOFARM

Jurnal Ilmiah Pertanian

ISSN Print: 0216-5430; ISSN Online: 2301-6442

Vol. 16, No. 1, April 2020

\title{
Pengaruh Variasi Dosis Legin Terhadap Pertumbuhan dan Produksi Kacang Hijau (Vigna radiata L.) pada Berbagai Tingkat Naungan
}

\section{Effect of Legin Dose Variation on Growth and Production of Mung Beans (Vigna radiata L.) at Various Shade Levels}

\author{
Sakinatunnisa ${ }^{1 \star}$ dan Syakiroh Jazilah ${ }^{1}$ \\ ${ }^{1}$ Program Studi Agroteknologi, Fakultas Pertanian, Universitas Pekalongan \\ *Korespondensi Penulis: sakinatunnisa23@gmail.com
}

\begin{abstract}
ABSTRAK
Kacang hijau (Vigna radiata L.) merupakan tanaman palawija yang memiliki peranan penting dalam memenuhi kebutuhan gizi masyarakat. Penelitian bertujuan untuk mengetahui pengaruh variasi dosis legin terhadap pertumbuhan dan produksi kacang hijau (Vigna radiata L) pada berbagai tingkat naungan dan interaksinya. Ini telah dilaksanakan di Desa Sijambe Kecamatan Wonokerto Kabupaten Pekalongan. Rancangan penelitian yang digunakan adalah Splitplot, perlakuan dosis sebagai sublot dan naungan sebagai mainplot. Faktor pertama dosis legin (D0= Kontrol, D1 = $10 \mathrm{~g} / \mathrm{kg}$ benih, D2 = $20 \mathrm{~g} / \mathrm{kg}$ benih, D3 = $30 \mathrm{~g} / \mathrm{kg}$ benih), faktor kedua tingkat naungan (N0 = Kontrol, N1 = Naungan $25 \%, \mathrm{~N} 2=$ Naungan $50 \%$ ). Data dianalisis dengan uji $\mathrm{F}$ dan jika terdapat perbedaan nyata dilakukan dengan uji BNT 5\%. Hasil penelitian menunjukkan bahwa dosis legin berbeda sangat nyata terhadap variabel tinggi tanaman, jumlah bintil akar, jumlah polong, berat polong kering, berat biji kering, berat 1000 biji dan berat brangkasan basah tanaman, hasil tertinggi dicapai pada dosis $20 \mathrm{~g} / \mathrm{kg}$ benih. Tingkat naungan berbeda sangat nyata terhadap terhadap variabel tinggi tanaman, jumlah cabang, jumlah polong, berat polong kering, berat biji kering dan beraat 1000 biji, diperoleh hasil tertinggi pada naungan kerapatan $25 \%(\mathrm{~N} 1)$. Interaksi antara dosis legin dan tingkat naugan berbeda sangat nyata terhadap variabel tinggi tanaman, jumlah polong, berat polong kering dan berat 1000 biji, pertumbuhan terbaik dicapai pada kombinasi dosis legin $20 \mathrm{~g} / \mathrm{kg}$ benih dan naungan $25 \%$ (D2N1).
\end{abstract}

Kata kunci : Kacang hijau (Vigna radiata L.), Legin, Naungan

\section{ABSTRACT}

Mung bean (Vigna radiata L.) is a palawija plant that has an important role in meeting the nutritional needs of the community. The study aims to determine the effect of variations in legin doses on the growth and production of green beans (Vigna radiata $L)$ at various shading levels and their interactions. This has been carried out in Sijambe Village, Wonokerto District, Pekalongan Regency. The study design used was Splitplot, the treatment of doses as a sublot and the shade as the mainplot. The first factor is the dose of legin ( $D 0=$ Control, $D 1=10 \mathrm{~g} / \mathrm{kg}$ of seed, $D 2=20 \mathrm{~g} / \mathrm{kg}$ of seed, $D 3=30 \mathrm{~g} / \mathrm{kg}$ of seed), the second factor is the shade level (NO = Control, N1 = Shade of 25\%, N2 = Shade of 50\%). Data were analyzed by F test and if there were real differences done by LSD test of $5 \%$. The results showed that the dose of legin was significantly different from the variable plant height, number of root nodules, number of pods, dry pod weight, dry seed weight, weight of 1000 seeds and the weight of the wet stover crop, the highest yield was achieved at a dose of $20 \mathrm{~g} / \mathrm{kg}$ of seed. The shade levels differ significantly with respect to the variable plant height, number of branches, number of pods, weight of dry pods, weight of dry seeds and 1,000 seed berries, the highest yield is obtained at 25\% (N1) shade shade. The interaction between legin dosage and naugan level was significantly different from plant height, number of pods, dry pod weight and weight of 1000 seeds, the best growth was achieved at a combination of $20 \mathrm{~g} / \mathrm{kg}$ seed legin dose and 25\% shade (D2N1).

Keywords: Mung Beans (Vigna radiata L.), Legin, Shade

\section{PENDAHULUAN}

Kacang hijau (Phaseolus radiatus L.) merupakan tanaman palawija yang memiliki peranan penting dalam memenuhi kebutuhan gizi masyarakat. Di Indonesia, kacang hijau menjadi produk penting dalam golongan kacang-kacangan setelah kedelai dan kacang tanah. Kacang hijau dapat dimanfaatkan sebagai bahan pangan dan pakan ternak. (Cahyono, 2008).
Menurut Badan Pusat Statistik (2019), pada tahun 2018 produksi tanaman kacang hijau adalah 112,162 ton. Data tersebut menurun dari tahun 2017 dimana produksi mencapai 123,228 ton. Penurunan produksi dapat mengurangi ketersediaan kacang hijau, sehingga perlu adanya peningkatan produksi. 
Beberapa permasalahan dalam pengem-bangan kacang hijau diantaranya adalah kurangnya ketersediaan benih unggul dan sarana produksi, penanganan pasca panen belum optimal, persaingan pemanfaatan lahan dengan komoditas pangan lain, terbatasnya permodalan petani dan kegiatan usaha tani masih konvensional (Andrianto dan Indarto, 2004).

Salah satu upaya untuk meningkatkan hasil kacang hijau diantaranya adalah dengan menggunakan legin dan naungan, legin merupakan inokulum yang mengandung bakteri Rhizobium. Bakteri Rhizobium adalah bakteri yang dapat bersimbiosis dengan tanaman legum dan termasuk bakteri penambat nitrogen (Ni'am dan Bintari, 2017).

Setiap tanaman mempunyai toleransi yang berlainan terhadap cahaya matahari. Ada tanaman yang tumbuh baik ditempat terbuka dan sebaliknya ada beberapa tanaman yang dapat tumbuh dengan baik pada tempat teduh atau di bawah naungan. Ada pula tanaman yang memerlukan intensitas cahaya yang berbeda sepanjang periode hidupnya (Faridah, 2006).

Budidaya tanaman kacang hijau sebagai tanaman sela di bawah tegakan tanaman perkebunan, hutan, tanaman industri atau secara tumpang sari dengan tanaman pangan lain merupakan strategi untuk meningkatkan produksi kacang hijau nasional. Namun dalam penanaman di bawah tanaman sela perlu diperhatikan varietas yang ditanam juga tingkat naungan yang dapat menjadi pembatas pertumbuhan dan hasil panen tanaman kacang hijau (Sundari, 2005). Berdasarkan uraian tersebut maka perlu dilakukan penelitian pengaruh dosis legin pada berbagai tingkat naungan terhadap pertum-buhan dan produksi kacang hijau.

Penelitian ini dilakukan dengan tujuan untuk mengetahui dosis legin yang optimum untuk memberikan hasil terbaik terhadap pertumbuhan dan produksi tanaman kacang hijau, untuk mengetahui presentase tingkat naungan yang tepat untuk pertumbuhan dan produksi tanaman kacang hijau dan untuk mengetahui interaksi antara dosis legin dan persentase naungan terhadap pertumbuhan dan produksi tanaman kacang hijau.

\section{METODE PENELITIAN}

Penelitian telah dilaksanakan di di Desa Sijambe, Kecamatan Wonokerto, Kabupaten Pekalongan, Jawa Tengah, mulai bulan November 2019 sampai Januari 2020 dengan ketinggian tempat $\pm 10 \mathrm{mdpl}$.
Rancangan yang digunakan dalam penelitian ini adalah Rancangan Split plot, disusun secara faktorial yang terdiri atas 2 faktor dosis legin sebagai sublot dan naungan sebagai mainplot. Faktor pertama adalah dosis legin yang terdiri atas $0 \mathrm{~g} / \mathrm{kg}$ benih (D0), $10 \mathrm{~g} / \mathrm{kg}$ benih (D1), $20 \mathrm{~g} / \mathrm{kg}$ benih (D2) dan 30 $\mathrm{g} / \mathrm{kg}$ benih (D3). Faktor kedua adalah naungan yang terdiri atas tanpa naungan (N0), naungan $25 \%$ (N1) dan naungan $50 \%$ (N2). 1500 ppm (N3). Masing-masing kombinasi diulang tiga kali dengan 12 kombinasi perlakuan sehingga seluruhnya ada 36 satuan percobaan. Satuan percobaan terdiri atas enam sampel tanaman sehingga seluruhnya ada $36 \times 6=216$ tanaman sampel.

Variabel yang diamati meliputi : tinggi tanaman, jumlah bintil akar, jumlah cabang, saat muncul bunga, jumlah polong, panjang polong terpanjang, berat polong kering, berat biji kering, berat 1000 biji dan berat brangkasan basah. Data dianalisis dengan analisis sidik ragam berdasarkan uji $\mathrm{F} 5 \%$ dan $1 \%$. Jika berpengaruh nyata dilanjutkan dengan uji BNT.

\section{HASIL DAN PEMBAHASAN Dosis Legin}

Hasil penelitian menunjukkan bahwa pe-ngaruh dosis legin berbeda sangat nyata terhadap variabel tinggi tanaman, jumlah bintil akar, jumlah polong, berat polong kering, berat biji kering, berat 1000 biji dan berat brangkasan basah tanaman. Hasil tertinggi dicapai pada dosis $20 \mathrm{~g} / \mathrm{kg}$ benih. Hal ini disebabkan bakteri rhizobium efisien dan efektif dalam ber-simbiosis dengan akar tanaman. Keberhasilan suatu inokulasi tergantung pada keefektifan dan efisiensi dari jenis strain yang berperan, dan mempunyai keserasian dengan tanaman inangnya (Sumarno dan Harnoto, 1983). Kelompok bakteri rhizobium ini akan meng-infeksi akar tanaman dan membentuk bintil akar di dalamnya. Kemampuan simbiosis yang efektif diketahui melalui terbentuknya bintil akar pada tanaman yang diinokulasi strain rhizobium, yang berarti proses penambatan nitrogen berjalan dengan baik (Demezas dan Bottomley ,1986).

Pemberian legin pada kacang hijau dalam jumlah banyak dapat memberikan pertumbuhan dan hasil tanaman yang lebih baik. Semakin tinggi dosis legin yang diberikan maka kandungan mikroorganisme yang ada semakin banyak, namun jika berlebihan juga akan merugikan tanaman. 
Tabel 1. Angka rata-rata dan Analisis Statistik Data Penelitian Pengaruh Variasi Dosis Legin dan tingkat naungan.

\begin{tabular}{ccccc}
\hline Perlakuan & $\begin{array}{c}\text { Tinggi tanaman } \\
(\mathrm{cm})\end{array}$ & $\begin{array}{c}\text { Jumlah bintil } \\
\text { akar per } \\
\text { tanaman (buah) }\end{array}$ & $\begin{array}{c}\text { Jumlah cabang } \\
\text { per tanaman } \\
\text { (buah) }\end{array}$ & $\begin{array}{c}\text { Saat muncul } \\
\text { bunga (hst) }\end{array}$ \\
\hline
\end{tabular}

\begin{tabular}{lcccc} 
Dosis Legin & & & \\
D0 $=0$ gram & $25,93 \mathrm{a}$ & $8,11 \mathrm{a}$ & 6,29 & $32,67 \mathrm{~b}$ \\
$\mathrm{D} 1=10$ gram & $30,84 \mathrm{~b}$ & $9,22 \mathrm{~b}$ & 6,31 & $33,00 \mathrm{c}$ \\
$\mathrm{D} 2=20$ gram & $34,04 \mathrm{~d}$ & $14,84 \mathrm{~d}$ & 6,98 & $32,33 \mathrm{a}$ \\
$\mathrm{D} 3=30$ gram & $32,65 \mathrm{c}$ & $12,36 \mathrm{c}$ & 6,31 & $3378 \mathrm{~d}$ \\
\hline Naungan & & & \\
$\mathrm{N} 0=$ Tanpa naungan & $31,02 \mathrm{~b}$ & 11,15 & $6,75 \mathrm{~b}$ & 97,5 \\
$\mathrm{~N} 1=25 \%$ & $34,20 \mathrm{c}$ & 12,65 & $6,92 \mathrm{c}$ & 99,75 \\
$\mathrm{~N} 2=50 \%$ & $27,38 \mathrm{a}$ & 9,6 & $5,75 \mathrm{a}$ & 99,25 \\
\hline $\begin{array}{l}\text { Keterangan: Keterangan : Angka yang dikuti huruf yang sama pada kolom dan baris menunjukkan tidak berbeda nyata } \\
\text { menurut uji BNT taraf 5\% }\end{array}$
\end{tabular}

Menurut Simanungkalit dkk., (2006) pemberian dosis pupuk hayati yang berlebihan akan menyebabkan terjadinya persaingan antar mikroba dalam memperoleh makanan sehingga akan berpengaruh terhadap kebutuhan nutrisi mikroba, akibatnya mikroba akan bekerja kurang optimal sehingga pengaruhnya terhadap tinggi tanaman juga kurang optimal. Pupuk hayati yang diberikan pada setiap perlakuan berbeda-beda dan hasilnya pun juga terlihat berbeda.

Semakin tinggi jumlah bahan organik, populasi mikroorganisme juga semakin tinggi (Singh dkk., 2008). Rhizobium tidak mampu melakukan pembintilan dari setiap tanaman legum, setiap kelompok dari spesies rhizobium mampu membentuk bintil akar dengan spesies legum yang berasal dari kelompok yang sama (Cheng, 2008).

Perkembangan bintil mulai terlihat pada umur 10-14 hari setelah tanam pada kondisi rumah kaca dan media bebas $\mathrm{N}$, pada kondisi lapang biasanya terlihat pada umur $21-28$ hari setelah tanam. Perkembangan bintil yang maksimum ditentukan oleh berat dan volumenya, dan umumnya terjadi pada akhir fase pembungaan (Uheda dkk,. 2001).

Kemampuan bintil akar dalam memfiksasi nitrogen ditentukan oleh kualitas bintil akar. Bintil akar yang efektif memfiksasi N2 berwarna merah karena mengandung leghemoglobin. Bintil akar tetap aktif selama 50 - 60 hari, setelah itu akan mengalami senescen. Pada saat senescen bakteroid dan leghemoglobin akan mengalami degradasi sehingga bintil akar berwarna hijau atau coklat. Bentuk, ukuran, warna, tekstur dan letak bintil akar pada tanaman ditentukan oleh tanaman inang (Dierolf, et al., 2001).

Menurut Triadiati (2013) inokulasi rhizobium efektif mempengaruhi pembentukan polong, polong yang telah terbentuk selanjutnya akan diisi oleh fotosintat sehingga terbentuklah biji. Pemanfaatan rhizobium sebagai inokulan dapat meningkatkan ketersediaan Nitrogen bagi tanaman, yang dapat mendukung peningkatan produktivitas tanaman kacangkacangan (Saraswati dan Sumarno, 2008).

\section{Tingkat Naungan}

Hasil penelitian menunjukkan perlakuan naungan berbeda sangat nyata terhadap variabel tinggi tanaman, jumlah cabang, jumlah polong, berat polong kering, berat biji kering dan beraat 1000 biji, diperoleh hasil tertinggi pada naungan kerapatan $25 \%$ (N1).

Tanaman kacang hijau termasuk spesies C3 yang mempunyai laju fotosintesis lebih kecil dari $\mathrm{C} 4$, oleh karena itu tanaman kacang hijau memerlukan $\mathrm{CO} 2$ dan sinar matahari yang lebih sedikit (Gardner, 1991). Tanaman C4 berbeda dengan tanaman C3 dalam beberapa hal termasuk dalam merespon cahaya dan suhu (Chinthapalli dkk,. 2002).

Kondisi lingkungan yang di kehendaki tanaman kacang hijau adalah daerah bersuhu $20^{\circ} \mathrm{C}-27^{\circ} \mathrm{C}$, kelembaban udara antara $50 \%$ $70 \%$ dan cukup mendapat sinar matahari (Rukmana, 2002). Serapan cahaya rendah menyebabkan perubahan metabolisme tanaman terutama serapan 
Tabel 2. Angka rata-rata dan Analisis Statistik Data Penelitian Pengaruh Variasi Dosis Legin dan tingkat naungan.

\begin{tabular}{|c|c|c|c|c|c|c|}
\hline Perlakuan & $\begin{array}{l}\text { Jumlah } \\
\text { polong } \\
\text { per tanaman } \\
\text { (buah) }\end{array}$ & $\begin{array}{l}\text { Panjang } \\
\text { polong } \\
\text { terpanjang } \\
\text { per } \\
\text { tanaman } \\
\text { (cm) }\end{array}$ & $\begin{array}{c}\text { Berat } \\
\text { polong } \\
\text { kering per } \\
\text { tanaman } \\
\text { (gram) }\end{array}$ & $\begin{array}{l}\text { Berat biji } \\
\text { kering per } \\
\text { tanaman } \\
\text { (gram) }\end{array}$ & $\begin{array}{c}\text { Berat } \\
1000 \\
\text { biji }(\mathrm{g})\end{array}$ & $\begin{array}{c}\text { Berat } \\
\text { brangkasan } \\
\text { basah per } \\
\text { tanaman }(\mathrm{g})\end{array}$ \\
\hline \multicolumn{7}{|l|}{ Dosis Legin } \\
\hline $\mathrm{D} 0=0$ gram & $16,57 a$ & 9,76 & $15,92 a$ & $16,50 a$ & $48,75 a$ & $100,42 a$ \\
\hline $\mathrm{D} 1=10$ gram & $24,37 b$ & 9,93 & $23,11 b$ & $18,18 b$ & $53,45 b$ & $100,45 a$ \\
\hline $\mathrm{D} 2=20 \mathrm{gram}$ & $29,00 d$ & 10,23 & $26,84 d$ & $22,50 d$ & $60,96 \mathrm{~d}$ & $116,64 c$ \\
\hline $\mathrm{D} 3=30 \mathrm{gram}$ & $26,03 \mathrm{c}$ & 10,01 & $24,60 c$ & $19,77 \mathrm{c}$ & $56,86 c$ & $106,88 b$ \\
\hline \multicolumn{7}{|l|}{ Naungan } \\
\hline N0 = Tanpa naungan & $22,31 b$ & $10,26 b$ & $22,83 b$ & $18,57 b$ & $55,51 b$ & 105,45 \\
\hline $\mathrm{N} 1=25 \%$ & $29,67 c$ & $9,80 a$ & $25,61 \mathrm{c}$ & $23,44 \mathrm{c}$ & $59,93 c$ & 105,49 \\
\hline $\mathrm{N} 2=50 \%$ & $20,00 \mathrm{a}$ & $9,89 a$ & $19,40 \mathrm{a}$ & $15,70 a$ & $49,58 a$ & 107,36 \\
\hline
\end{tabular}

karbohidrat, karbohidrat yang rendah dapat berpengaruh terhadap serapan ion, respirasi dan konsentrasi pati di akar. Pengiriman karbohidrat melalui floem yang digunakan sebagai sinyal ke akar terhadap tingkat serapan $\mathrm{N}$ dan $\mathrm{P}$ menyebabkan pertumbuhan tanaman tidak maksimal (Marscner 2012). Menurut Afandi dkk., (2013), tingkat naungan berpengaruh nyata terhadap tinggi tanaman dan jumlah cabang.

Suatu enzim dapat mempercepat reaksi 8 sampai 10 kali lebih cepat, enzim juga menurunkan atau memeprkecil energi aktivasi suatu reaksi kimia (Poedjiadi dan Supriyanti, 2009). Setiap enzim memiliki aktivitas maksimum pada suhu tertentu, aktivitas enzim akan semakin meningkat dengan bertambahnya suhu hingga suhu

Tabel 3. Angka rata-rata Interaksi Penelitian Pengaruh Variasi dosis legin dan tingkat naungan

\begin{tabular}{ccccccc}
\hline $\begin{array}{c}\text { Kombinasi } \\
\text { perlakuan }\end{array}$ & $\begin{array}{c}\text { Tinggi } \\
\text { tanaman } \\
\text { (cm) }\end{array}$ & $\begin{array}{c}\text { Jumlah bintil } \\
\text { akar per } \\
\text { tanaman } \\
\text { (buah) }\end{array}$ & $\begin{array}{c}\text { Jumlah } \\
\text { polong per } \\
\text { tanaman } \\
\text { (buah) }\end{array}$ & $\begin{array}{c}\text { Berat polong } \\
\text { kering per } \\
\text { tanaman }(\mathrm{g})\end{array}$ & $\begin{array}{c}\text { Berat biji } \\
\text { kering per } \\
\text { tanaman }(\mathrm{g})\end{array}$ & $\begin{array}{c}\text { Berat } 1000 \\
\text { biji }(\mathrm{g})\end{array}$ \\
\hline D0N0 & $27,33 \mathrm{~b}$ & $7,87 \mathrm{ab}$ & $18,23 \mathrm{~b}$ & $16,63 \mathrm{~b}$ & $15,61 \mathrm{e}$ & $47,61 \mathrm{~b}$ \\
D1N0 & $30,07 \mathrm{~cd}$ & $9,47 \mathrm{bc}$ & $21,53 \mathrm{c}$ & $23,68 \mathrm{ef}$ & $17,37 \mathrm{~d}$ & $50,94 \mathrm{c}$ \\
D2N0 & $34,37 \mathrm{f}$ & $14,80 \mathrm{~g}$ & $26,40 \mathrm{f}$ & $26,36 \mathrm{~g}$ & $22,41 \mathrm{~g}$ & $63,70 \mathrm{~g}$ \\
D3N0 & $32,41 \mathrm{e}$ & $12,47 \mathrm{ef}$ & $23,07 \mathrm{~d}$ & $24,67 \mathrm{f}$ & $18,89 \mathrm{e}$ & $59,77 \mathrm{f}$ \\
D0N1 & $26,60 \mathrm{~b}$ & $8,80 \mathrm{abc}$ & $18,60 \mathrm{~b}$ & $16,91 \mathrm{~b}$ & $21,13 \mathrm{f}$ & $52,60 \mathrm{~d}$ \\
D1N1 & $35,27 \mathrm{f}$ & $9,53 \mathrm{bc}$ & $30,67 \mathrm{~g}$ & $26,42 \mathrm{~g}$ & $22,82 \mathrm{~g}$ & $61,31 \mathrm{f}$ \\
D2N1 & $39,53 \mathrm{~g}$ & $18,13 \mathrm{~h}$ & $36,20 \mathrm{i}$ & $31,22 \mathrm{i}$ & $25,55 \mathrm{i}$ & $66,04 \mathrm{~h}$ \\
D3N1 & $35,40 \mathrm{f}$ & $14,13 \mathrm{fg}$ & $33,20 \mathrm{~h}$ & $27,91 \mathrm{~h}$ & $24,27 \mathrm{~g}$ & $59,77 \mathrm{f}$ \\
D0N2 & $23,87 \mathrm{a}$ & $7,67 \mathrm{a}$ & $12,87 \mathrm{a}$ & $14,22 \mathrm{a}$ & $12,76 \mathrm{a}$ & $46,03 \mathrm{a}$ \\
D1N2 & $27,20 \mathrm{~b}$ & $8,67 \mathrm{ab}$ & $20,90 \mathrm{c}$ & $19,23 \mathrm{c}$ & $14,34 \mathrm{~b}$ & $48,10 \mathrm{c}$ \\
D2N2 & $28,33 \mathrm{bc}$ & $11,60 \mathrm{de}$ & $24,40 \mathrm{e}$ & $22,95 \mathrm{e}$ & $19,55 \mathrm{e}$ & $53,16 \mathrm{e}$ \\
D3N2 & $30,13 \mathrm{~d}$ & $10,47 \mathrm{~cd}$ & $21,83 \mathrm{c}$ & $21,21 \mathrm{~d}$ & $16,16 \mathrm{e}$ & $51,02 \mathrm{~cd}$
\end{tabular}

Keterangan : Keterangan : Angka yang diikuti huruf yang sama pada kolom dan baris menunjukkan tidak berbeda nyata menurut uji BNT taraf $5 \%$ 
optimum tercapai. Setelah itu kenaikan suhu lebih lanjut akan menyebabkan aktivitas enzim menurun (Megiadari, 2009).

Perlakuan naungan memberikan kondisi iklim mikro yang sesuai untuk pembentukan biji per polong kacang hijau, karena terjadinya keseimbangan pengaturan suhu dan kelembabannya. Penerimaan cahaya matahari sangat berdampak pada pembentukan polong dan biji per polong kacang hijau (Suparwata, 2018).

\section{Pengaruh Interaksi Antara Dosis Legin dan Tingkat Naungan}

Hasil penelitian menunjukkan bahwa terdapat interaksi anatar dosis legin dan naungan berbeda sangat nyata terhadap variabel tinggi tanaman, jumlah polong, berat polong kering dan berat 1000 biji, pertumbuhan terbaik dicapai pada dosis legin $20 \mathrm{~g} / \mathrm{kg}$ benih dan naungan $25 \%$ (D2N1).

Hasil penelitian menunjukkan adanya interaksi antara dosis legin $20 \mathrm{~g} / \mathrm{kg}$ benih dan naungan $25 \%$. Hal ini disebabkan pemberian legin dengan dosis $20 \mathrm{~g} / \mathrm{kg}$ benih membantu tanaman membentuk bintil akar yang dapat menambat $\mathrm{N}$ dari udara sehingga kebutuhan $\mathrm{N}$ dari tanaman kacang hijau tercukupi, didukung dengan naungan yang tepat yaitu naungan $25 \%$ atau N1. Menuurut Fransisca (2009) unsur hara yang terserap akar salah satunya adalah unsur hara N. Ketersediaan unsur hara yang meningkat berpengaruh terhadap pembelahan sel sehingga mempengaruhi pertumbuhan dan perkembangan akar tanaman.

Hasil penelitian menunjukkan bahwa tanaman kacang hijau dapat beradaptasi pada naungan $25 \%$. Hal ini disebabkan dengan hasilnya yang lebih tinggi dibandingkan dengan naungan $50 \%$ atau N2. Menurut Sundari dkk., (2005) bahwa persaingan cahaya merupakan salah satu faktor penyebab tingginya penurunan hasil kacang hijau. Perbedaan produksi yang diperoleh disebabkan oleh perbedaan tingkat naungan dan iklim mikro yaitu intensitas cahaya, suhu dan kelembaban.

\section{Simpulan}

Berdasarkan hasil penelitian dan pembahasan dapat ditarik beberapa simpulan sebagai berikut :

1. Perlakuan dosis legin berbeda sangat nyata terhadap variabel tinggi tanaman, jumlah bintil akar, jumlah polong, berat polong kering, berat biji kering, berat 1000 biji dan berat brangkasan basah. Dosis legin $20 \mathrm{~g} / \mathrm{kg}$ benih (D2) memberikan pertumbuhan terbaik pada tanaman kacang hijau.

2. Perlakuan naungan berbeda sangat nyata terhadap variabel tinggi tanaman, jumlah cabang, jumlah polong, berat polong kering, berat biji kering dan berat 1000 biji. Naungan $25 \%$ (N1) memberikan pertmbuhan terbaik pada tanaman kacang hijau.

3. Interaksi antara dosis legin dan naungan berbeda sangat nyata terhadap variabel tinggi tanaman, jumlah polong, berat polong kering dan berat 1000 biji. Pertumbuhan terbaik dicapai pada kombinasi perlakuan dosis legin $20 \mathrm{~g} / \mathrm{kg}$ benih dan naungan $25 \%$ (D2N1).

\section{DAFTAR PUSTAKA}

Afandi, M., Mawarni, L., dan Syukri. (2013). Respon Pertumbuhan dan Produksi Empat Varietas Kedelai (Glycine max L.) terhadap Tingkat Naungan. Jurnal Agroekoteknologi, 1(2): 214-226.

Andrianto, T.T. dan N. Indarto. 2004. Budidaya dan Analisis Usaha Tani Kedelai, Kacang Hijau, Kacang Panjang. Absolut. Yogyakarta.

Badan Pusat Statistik. 2019. Tanaman Pangan dan Hortikultura Provinsi Jawa Tengah. BPS, Jawa Tengah.

Cahyono. 2008. Kacang hijau (teknik budidaya kacang hijau). Aneka ilmu. Semarang.

Cheng. 2008. Perspectives in biological nitrogen fixing research. Jurnal of Integrative Plant Biology. 50 : 784796.

Chinthapalli B, Murmu J, Raghavendra AS. 2002. Dramatic difference in the responses of phosphoenolpyruvate carboxylaseto temperature in leaves of $\mathrm{C} 3$ and $\mathrm{C} 4$ plants. $J$ Exp Bot 54:707-714

Demezas DH and PJ Bottomley. 1986. Antecology in rhizosphere and nodulating behavior of indigenous Rhizobium trifolii. Applied and Enviromental Microbiology 52(4-6), 1014-1019.

Dierolf, T., T. Fairhurst dan E. Mutert. 2001. Soil Fertility Kit. Potash \& Phosphate Institute of Canada.

Faridah E, 2006. Pengaruh Intensitas Cahaya, Mikoriza Dan Serbuk Arang Pada Pertumbuhan Alam Drybalanops Sp. Skripsi. Fakultas Kehutanan Universitas Gadjah Mada Yogyakarta. 
Fransisca, S. 2009. Respon Pertumbuhan dan Produksi Sawi (Brassica Juncea L.) terhadap Penggunaan Pupuk Kascing dan Pupuk Organik Cair. Skripsi. Fakultas Pertanian. Universitas Sumatera Utara, Medan.

Gardner, F.P. 1991. Fisiologi Tanaman Budidaya. Universitas Indonesia Press. Jakarta.

Marscner, P. 2012. Mineral Nutrition Of Hingher Plants Third Edition. San Diego USA. 23-24

Megiandari, A. 2009. Isolasi Dan Pencirian Enzim Protease Keratinolitik Dari Usus Biawak Air . [Tesis] Jurusan Kimia FMIPA. IPB. Bogor.

Ni'am A.M dan Bintari S.H. 2017. Pengaruh Pemberian Inokulan Legin dan Mulsa terhadap Jumlah Bakteri Bintil Aq kar dan Pertumbuhan Tanaman Kedelai Varietas Grobogan. Jurnal MIPA 40 (2) (2017) : 80-86.

Poedjiadi, A., Supriyanti, F.M.T. 2009. DasarDasar Biokimia. Penerbit Universitas Indonesia. Jakarta

Rukmana. 2002. Budidaya kacang-kacangan. Kansinus. Yogyakarta.

Saraswati, R. Dan Sumarno. 2008. Pemanfaatan Mikroba Penyubur Tanah sebagai Komponen Teknologi Pertanian. Puslitbang. Jakarta. Jurnal Iptek Tanaman Pangan. 3(1): 41-54.

Simanungkalit, R.D.M , T. Hutagalung, R.D. Hastuti, E. Pratiwi, and R.J. Roughley. 2006. Effectiveness of Bradyrhizobium phaseoli strains selected for acid-tolerance to increase yields of soybean grown in acid soils in Indonesia. Indonesian J. Crop Sci. 13: 32-40.
Singh. 2008. Characterization of Rhizobium Strain Isolated from the Roots of Trigonella foenumgraecum (fenugreek). African Journal of Biotechnology. 7(20): 36713676.

Sumarno dan Harnoto. 1983. Kedelai dan Cara bercocok Tanamnya. Pusat Penelitian dan pengembangan Tanaman pangan. Buletin Tehnik 6, 63 .

Sundari, T., Soemartono., Tdeohari., dan Mangoendidjojo, W. 2005. Keragaan Hasil dan Toleransi Genotip Kacang Hijau Terhadap Penaungan. IImu Pertanian 12 (1) : 12-19.

Suparwata, D.O. 2018. Respon Pertumbuhan Dan Produksi Kacang Hijau (Vigna radiata L.) Terhadap Perlakuan Perbedaan Naungan. Akademika Jurnal IImiah UMG 7 (1)

Triadiati, Nisa R, dan Yoan R. 2013. Respon Pertumbunan Tanaman Kedelai terhadap Bradyrhizobium japonicum Toleran Masam dan Pemberian Pupuk di Tanah Masam. Agron. Indonesia. 41 (1): 24-31.

Uheda E., H. Daimon and F. Yoshizako. 2001. Colonization and Invasion of Peanut (Arachis hypogaea L.) roots by gusA-marked Bradyrhizobium sp. Canadian Journal of Botany 79:7 